\title{
What is an appropriate blood pressure goal for the elderly: review of recent studies and practical recommendations
}

This article was published in the following Dove Press journal:

Clinical Interventions in Aging

13 November 2013

Number of times this article has been viewed

\section{Matthew G Denker \\ Debbie L Cohen}

Perelman School of Medicine, Renal, Electrolyte and Hypertension

Division, University of Pennsylvania, Philadelphia, PA, USA
Correspondence: Debbie L Cohen Perelman School of Medicine, Renal, Electrolyte and Hypertension Division, University of Pennsylvania, I Founders Building, 3400 Spruce Street,

Philadelphia, PA, 19104, USA

$\mathrm{Tel}+\mathrm{I} 2156627934$

Fax +I 2I5 6150349

Email debbie.cohen@uphs.upenn.edu

\begin{abstract}
Hypertension is common in the elderly, and isolated systolic hypertension is responsible for the majority of hypertension in this population. Hypertension in the elderly can be attributed to numerous structural and functional changes to the vasculature that develop with advancing age. Increased systolic blood pressure is associated with adverse outcomes, including stroke, cardiovascular disease, and death. Some studies demonstrate an inverse relationship between cardiovascular outcomes and diastolic blood pressure whereas other studies show a J-shaped or U-shaped association between blood pressure and outcomes. The complex J-shaped association coupled with the unique characteristics of elderly patients have led to much debate and confusion regarding the treatment of hypertension in this population. Clinical trials indicate a benefit to therapy in older adults, and there appears to be no age threshold above which antihypertensive therapy should be withheld. Treatment of hypertension in elderly patients is further complicated by increased susceptibility to brain hypoperfusion with orthostatic hypotension as well as the risk of drug-drug interactions. We recommend a systolic blood pressure goal of $<140 \mathrm{mmHg}$ in patients less than 80 years of age and a systolic blood pressure goal of $140-150 \mathrm{mmHg}$ in patients 80 years of age or older. Reduction of blood pressure is probably more important than the specific agent used and initiation of drug therapy with an angiotensin converting enzyme inhibitor, angiotensin receptor blocker, calcium channel blocker, or diuretic are all reasonable options, and the decision should be individualized based on underlying comorbidities.
\end{abstract}

Keywords: hypertension, blood pressure target, antihypertensive treatment, elderly

\section{Introduction}

Elderly patients represent an ever-growing subgroup of the US population, with an estimated 36 million Americans $\geq 65$ years of age. ${ }^{1}$ As blood pressure (BP) tends to increase with age, hypertension is exceedingly common in the elderly with an estimated prevalence of $67 \%$ for adults aged 60 or older, ${ }^{2}$ and in adults aged 55 to 65 , the lifetime risk of developing hypertension is estimated to be $90 \% .{ }^{3}$ Compared to younger adults, older adults are more likely to be aware of a diagnosis of hypertension and receive treatment for it. Older patients, however, are less likely to achieve BP control once treated, and this may be due to a variety of reasons including resistant hypertension, ${ }^{4}$ adherence patterns to treatment regimens, different BP goals for elderly patients used by different physicians, and lengthy and complex hypertension guidelines leading to "therapeutic inertia." Hypertension is associated with considerable morbidity and an increased risk of cardiovascular disease (CVD), stroke, decreased quality of life, and mortality in the elderly. ${ }^{5-8}$ Despite the almost universal prevalence of hypertension 
in the elderly, this population represents a unique subgroup of patients with hypertension due to the fact that there are relatively few clinical trials that have been conducted in the elderly. Historically, most clinical hypertension trials excluded elderly patients. Clinical trials have also not specifically addressed the risk of adverse events with treatment, which are particularly important in this population and include issues related to drug interactions and side effects of antihypertensive medications, such as orthostatic hypotension in the setting of autonomic dysregulation. This review will focus on the mechanisms and patterns of BP change with age as well as discuss results from published clinical trials in the elderly and how they differ from clinical practice guidelines in attempt to recommend a goal BP for this population.

\section{Pathophysiology and vascular changes with age and the relationship to hypertension and CVD}

CVD is the most common cause of death in elderly adults and age-related changes to the vasculature play a major role in vulnerability to CVD. Arterial aging (eg, arteriosclerosis) leads to consequences of isolated systolic hypertension (ISH), diastolic heart failure, and small vessel disease in the brain and other organs. ISH, defined as systolic BP (SBP) greater than or equal to $140 \mathrm{mmHg}$ with diastolic BP (DBP) less than $90 \mathrm{mmHg}$, accounts for $87 \%$ of hypertension cases in older adults $;{ }^{9}$ and elevated SBP is more strongly associated with cardiovascular $(\mathrm{CV})$ risk than DBP in the elderly. ${ }^{10}$ Data from the National Health and Nutrition Education Survey (NHANES)
III demonstrate a progressive rise in SBP with age, yet DBP typically peaks in the sixth decade of life and falls thereafter (Figure 1), ${ }^{11}$ resulting in ISH coupled with a widened pulse pressure. Structural and functional alterations occur in the vasculature in response to normal aging, which provide an understanding for this pattern of change in BP in the elderly (Table 1). These alterations are most prominent in the proximal aorta and are underestimated by brachial sphygmomanometer cuff pressure. Fracture of elastic lamellae causes dilation and stiffening of blood vessels, a condition previously referred to as "senile arteriosclerosis." Increased arterial stiffness, due to increased intima-media thickness and collagen accumulation produced by invading vascular smooth muscle cells (VSMCs), results in an increase in aortic pulse wave velocity and thus, early return of the reflected pressure wave and elevation in systolic pressure. ${ }^{12}$ Decreased elasticity of the aorta also results in greater peripheral runoff during systole. ${ }^{12}$ Therefore, with less blood in the aorta during diastole, DBP falls.

Animal studies suggest that angiotensin II plays an integral role in vascular aging, ${ }^{13,14}$ which may be related to increased oxidative stress. ${ }^{15}$ Angiotensin II signaling, including calpain-1 and matrix metalloproteinase type II (MMP2) activation, has been linked to an age-associated increase in migration capacity of VSMCs. Infusion of angiotensin II into rats leads to carotid media thickening and intima infiltration by VSMCs, which resembles the arterial remodeling of aging. ${ }^{14}$ Furthermore, chronic administration of angiotensin converting enzyme (ACE) inhibitors or angiotensin II type-1 receptor blockers (ARBs) to rats confers cardiovascular
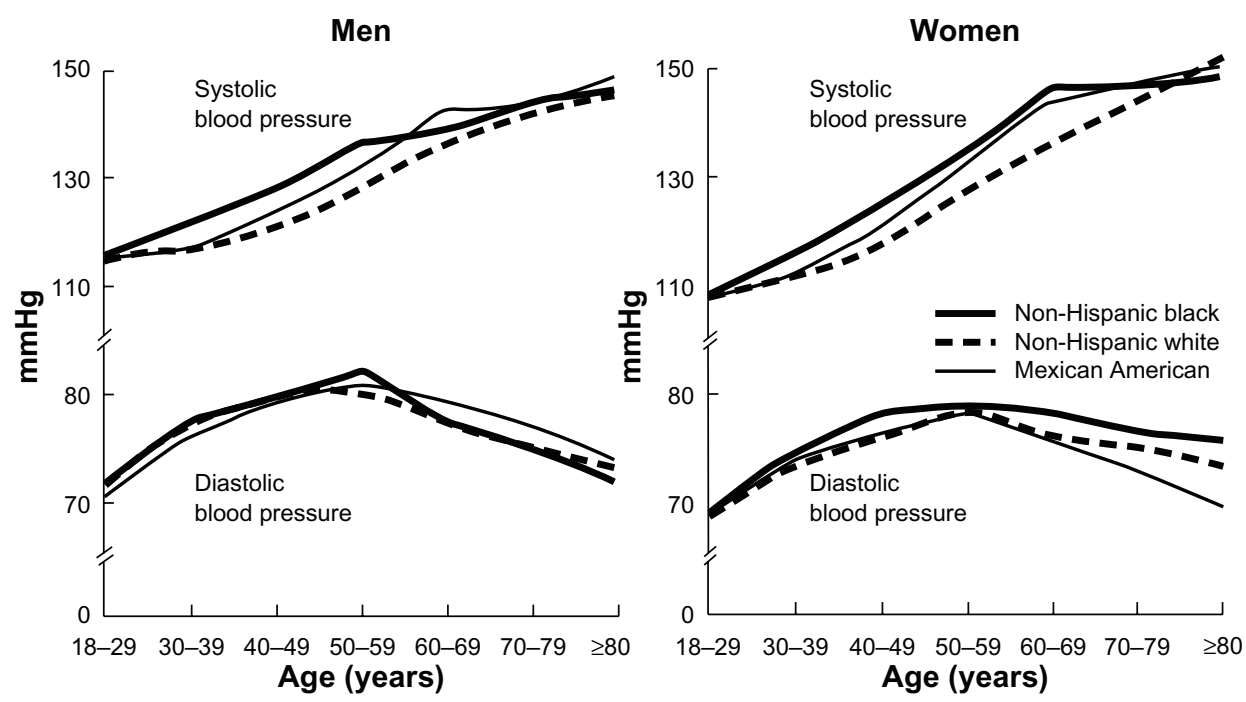

Figure I Mean SBP and DBP by age, race/ethnicity, and sex in the US population; data from NHANES III.

Notes: Reprinted with permission from LippincottWilliams andWilkins/Wolters Kluwer Health: Hypertension, BurtVL,Whelton P, Roccella EJ, et al, Prevalence of hypertension in the US adult population, Results from the Third National Health and Nutrition Examination Survey, 1988-1991, 1995;25(3):305-313." Copyright (C) I995. Promotional and commerical use of the material in print, digital or mobile device format is prohibited without the permission from the publisher Lippincott Williams and Wilkins. Please contact journalpermissions@lww.com for further information.

Abbreviations: DBP, diastolic blood pressure; NHANES, National Health and Nutrition Education Survey; SBP, systolic blood pressure. 
Table I Factors associated with increased blood pressure in elderly patients

Increased vascular stiffness

Decreased elastin content in the vessel wall

Increased endothelial dysfunction

Increased salt sensitivity

Increased sympathetic activity

Comorbid conditions

Chronic kidney disease

Obesity

White-coat effect

protection and reduces the vascular effects of aging. ${ }^{16}$ In addition to the aforementioned structural changes to the vasculature, aging is associated with functional changes, such as increased sympathetic activity. ${ }^{17}$ Baroreceptor sensitivity to changes in BP decreases with age, resulting in higher levels of catecholamines accompanied by vasoconstriction. ${ }^{18}$

While findings from animal models may shed an interesting light on vascular aging in humans, studies in humans are needed to investigate a potential role for specific anti-aging therapies. Exercise exerts numerous beneficial effects and is considered vasoprotective, likely, at least in part, via improving endothelial function and reducing inflammation. ${ }^{12,19}$ Though studies support the role of oxidative stress in the pathogenesis of hypertension and CVD, trials of antioxidants (eg, vitamins $\mathrm{C}$ and $\mathrm{E}$ ), while promising in animals, ${ }^{20,21}$ have largely been disappointing in terms of reducing major $\mathrm{CV}$ endpoints in humans. ${ }^{22-24}$ However, these vitamins have only weak antioxidant properties. On the other hand, perhaps some of the benefit derived from $\mathrm{ACE}$ inhibitors, $\mathrm{ARBs}$, and calcium channel blockers (CCBs) is mediated by their ability to improve endothelial function and reduce oxidative stress. ${ }^{25-28}$

Alterations in the vasculature are accompanied by a cascade of changes in cardiac structure and function that occur with age and contribute to CV morbidity and mortality. Elevated systolic pressure increases left ventricular load, which results in left ventricular hypertrophy (LVH). The hypertrophied ventricle contracts more slowly, thus prolonging systole. Myocardial oxygen demand is increased due to LVH yet oxygen supply is decreased due to shorter duration of diastole, lower diastolic pressure, and coronary atherosclerosis. This supply-demand mismatch may predispose to ischemia, which contributes to a vicious cycle of impaired relaxation, shorter diastole, and further decrease in oxygen supply. In addition, impaired relaxation is accompanied by incomplete left ventricular filling as well as increased left atrial and pulmonary pressure, which are features of diastolic heart failure - the most common form of heart failure in the elderly.

\section{J-shaped relationship between BP and outcomes}

Observational data demonstrate a consistent relationship between the degree of elevation in SBP and risk of CVD and stroke. ${ }^{7,8,10,29}$ This relationship does not prove that treating BP to lower target levels results in fewer events; and overaggressive treatment of BP may actually lead to hypoperfusion of vital organs. In fact, for a given level of SBP, risk of death increases for each decrement in DBP (Figure 2). ${ }^{30}$ These contrasting relationships add another layer of complexity to treatment of BP in elderly patients, especially considering the general trend of ISH coupled with a decrease in DBP in the presence of decreased arterial compliance. However, many other studies demonstrate a J-shaped association between $\mathrm{BP}$ and $\mathrm{CV}$ outcomes; ie, increased risk at both low and high BP (Figure 3), ${ }^{31-34}$ which may contribute to the tempered enthusiasm of some physicians for the treatment of BP in the elderly.

These findings have been replicated in multiple population-based cohorts; and while the association between low BP and worse outcomes may be partially explained by overall health status or presence of comorbid conditions, ${ }^{35}$ some studies demonstrate persistence of this association even after controlling for comorbidities. ${ }^{36-38}$ The combination of low SBP and DBP may represent a distinct group of patients with certain comorbidities (such as heart failure) or may be

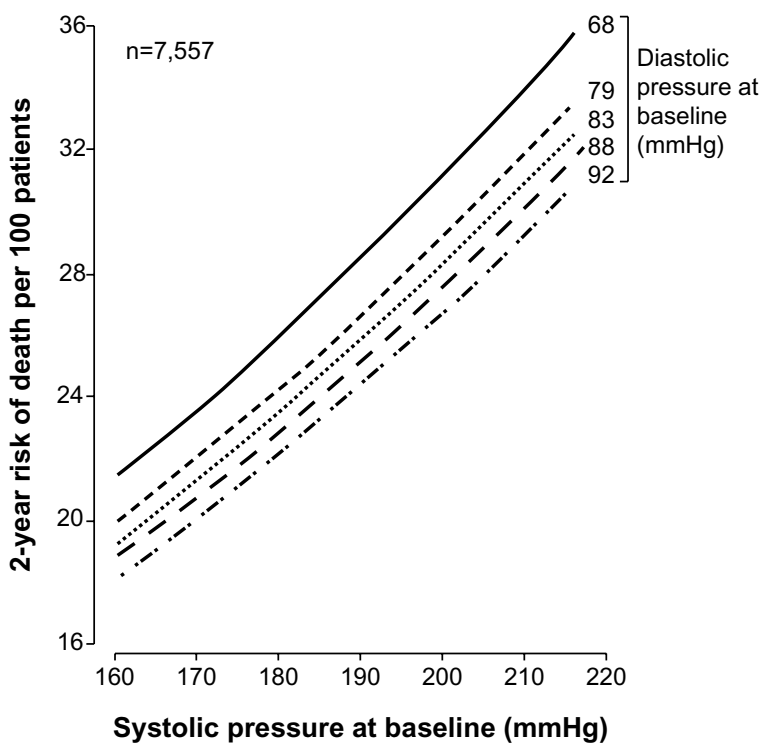

Figure 2 Risk of death in control patients of select randomized controlled trials according to baseline SBP and DBP.

Notes: Reprinted from The Lancet, 355(9207), Staessen JA, Gasowski J, Wang JG, et al Risks of untreated and treated isolated systolic hypertension in the elderly: meta-analysis of outcome trials, 865-872. ${ }^{30}$ Copyright (C) 2000, with permission from Elsevier. Abbreviations: DBP, diastolic blood pressure; SBP, systolic blood pressure. 

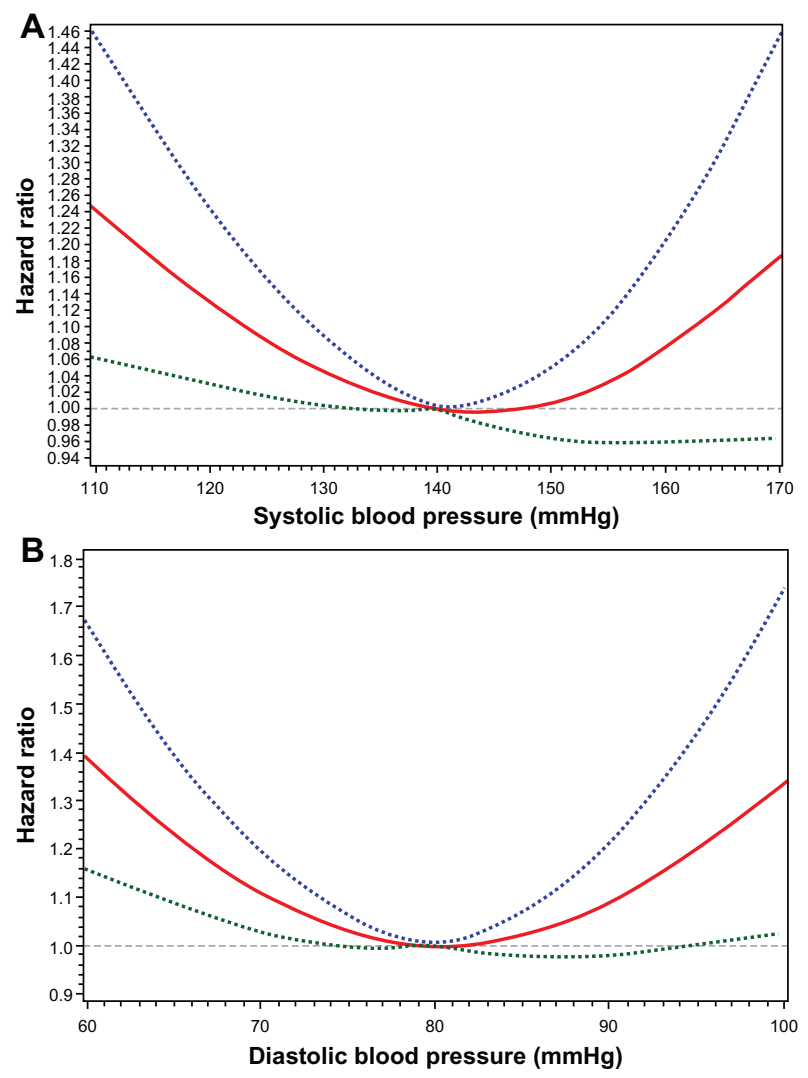

Figure 3 Adjusted hazard ratio for major CV event in relation to SBP (A) and DBP (B) from the Treating to New Targets (TNT) trial. Dotted lines denote upper and lower bounds of the $95 \%$ confidence interval.

Notes: Reprinted from Eur Heart J, 3I(23), Bangalore S, Messerli FH, Wun CC, et al; Treating to New Targets Steering Committee and Investigators. J-curve revisited: An analysis of blood pressure and cardiovascular events in the Treating to New Targets (TNT) Trial, 2897-2908..$^{34}$ Copyright (C) 2010, with permission from Oxford University Press.

Abbreviations: CV, cardiovascular; DBP, diastolic blood pressure; SBP, systolic blood pressure.

indicative of poorer overall health that was not fully adjusted for in statistical models.

In a population-based study performed in a Swedish cohort of the very elderly, ${ }^{39}$ participants were stratified into four groups of SBP ( $\leq 120 \mathrm{mmHg}, 121-140 \mathrm{mmHg}, 141-$ $160 \mathrm{mmHg}$, or $>160 \mathrm{mmHg}$ ). Single BP measurements were taken at baseline, and comorbidity and medication data were collected only at baseline. The primary outcome of the study was 4-year all-cause mortality. Consistent with other studies, SBP was found to be more strongly associated with mortality than DBP. The association between DBP and mortality lost statistical significance in multivariable models. In multivariable-adjusted models, the highest risk of death was associated with SBP $\leq 120 \mathrm{mmHg}$. Furthermore, a U-shaped mortality curve was seen with the nadir of risk being associated with the two SBP categories representing the range $121-160 \mathrm{mmHg}$, with these two categories demonstrating similar risk. When the coefficients from the final regression model were used to derive a U-curve for mortality risk, the minimum point of the curve corresponded to SBP of $164 \mathrm{mmHg}$. Though it has been suggested that the low BP-higher mortality association manifests only close to death, the investigators performed a sensitivity analysis that excluded deaths within the first year of follow-up; and this analysis revealed that the association persisted, demonstrating robustness of their findings.

Another population-based observational study that was performed at four centers in the United States revealed complex relationships between the modifying effects of sex and age on the association between BP and mortality. ${ }^{40}$ This study followed 12,802 participants aged 65 years or older, 1,088 of whom were 85 years or older. The investigators assessed whether the association between BP and 6-year mortality differed by age category ( $<85$ or $\geq 85$ years) and sex. Subjects in the older age group were more likely to be hospitalized in the previous year, be dependent in activities of daily living, and have a body mass index $<22 \mathrm{~kg} / \mathrm{m}^{2}$. In models adjusted for a number of demographic and comorbid conditions, there was a statistically significant $4 \%$ increased hazard of death in men in the $<85$ year old group but an $8 \%$ decreased hazard of death in men in the $\geq 85$ year old group for each $10 \mathrm{mmHg}$ increase in SBP. Hazard of death increased for each $10 \mathrm{mmHg}$ increase in SBP in women in the younger age group but no difference was seen in the $\geq 85$ year old group. U-shaped curves of risk showed that the lowest risk of death corresponded to SBP of $134 \mathrm{mmHg}$ and $182 \mathrm{mmHg}$ for the younger and older men, respectively.

The results of these and other studies suggest that the optimal BP in very elderly patients may be higher than previously thought. Results from observational studies must be interpreted with caution as they may not be able to fully adjust for greater comorbidity burden, do not prove cause-and-effect relationships, and should not replace well-conducted clinical trials. Finally, in a meta-analysis of seven randomized controlled trials (RCTs), five of which were performed in the elderly, this J-curve phenomenon was seen in both the active treatment and placebo groups. ${ }^{41}$

\section{Evidence for BP treatment}

Despite a recommended goal BP of $<140 / 90 \mathrm{mmHg}$ in The Seventh Report of the Joint National Committee on Prevention, Detection, Evaluation, and Treatment of High Blood Pressure (JNC VII) ${ }^{42}$ there is little evidence to support this recommendation for elderly patients. In fact, prior to the studies described below, elderly patients were either excluded from randomized trials or were recruited in too few numbers to ascertain outcome data. Furthermore, a BP goal higher than 140/90 mmHg was targeted in randomized controlled trials (RCTs) in elderly patients, 
which is acknowledged in the recent set of guidelines put forth by the European Society of Hypertension (ESH) and European Society of Cardiology (ESC).$^{43}$ Of note, given the high overall burden of cardiovascular events in the elderly, even modest reductions in relative risk with treatment of hypertension likely represents important reductions in absolute risk.

As in younger patients, lifestyle modifications including exercise ${ }^{44}$ dietary sodium restriction, ${ }^{45}$ limiting alcohol consumption, and weight loss if appropriate have been shown to reduce BP in elderly patients with hypertension and thus, should be recommended to elderly patients.

The landmark hypertension trials involving elderly patients are described in Table 2. In order to formulate our recommendations, we selected RCTs for inclusion in this review if the cohorts were comprised of patients either exclusively $\geq 60$ years of age or if patients $\geq 60$ years of age represented the majority of the cohort. The first doubleblind RCT to study antihypertensive drug treatment in the elderly was conducted in $1972 .{ }^{46}$ The European Working Party on High blood pressure in the Elderly (EWPHE) trial recruited patients over the age of 60 years with SBP 160-239 mmHg and DBP 90-119 mmHg. Eight hundred forty patients were randomized to active treatment with diuretics (hydrochlorothiazide plus triamterene) or placebo. Diuretic doses could be increased or methyldopa added in the treatment group if necessary. Mean age of the study participants was 72 years. Mean BP at randomization was $183 / 101 \mathrm{mmHg}$ and $182 / 101 \mathrm{mmHg}$ in the active treatment and placebo groups, respectively. The study's major findings were a non-significant reduction in all-cause mortality, nonsignificant reduction in stroke mortality, and a significant $27 \%$ reduction in $\mathrm{CV}$ mortality $(P=0.037)$ in the active treatment group.

The Systolic Hypertension in the Elderly Program (SHEP) trial randomized patients 60 years or older with ISH to active treatment with chlorthalidone or placebo. ${ }^{47}$ Goal BP for the active treatment group was SBP $<160 \mathrm{mmHg}$ and decrease from baseline SBP of $\geq 20 \mathrm{mmHg}$. Atenolol could be added in the active treatment group if BP goal was not achieved. Mean follow-up was 4.5 years. At 5 years, BP was $143 / 68 \mathrm{mmHg}$ versus $155 / 72 \mathrm{mmHg}$ in the active treatment and placebo groups, respectively. Active treatment was associated with a $36 \%$ reduction in the primary endpoint (ie, fatal or nonfatal stroke), which was statistically significant $(P=0.0003)$. Further, cumulative incidence curves for stroke began to noticeably diverge after approximately 1 -year. In a stratified analysis by age category (60-69 years, 70-79 years, 80 years or older), the incidence rate of stroke was lower in the active treatment group in all strata. Active treatment was also associated with significant reductions in $\mathrm{CV}$ events as well as non-significant reductions in all-cause mortality and CV mortality. In a post hoc analysis of the SHEP trial that investigated various levels of in-trial BP on risk of stroke, participants with SBP $<150 \mathrm{mmHg}$ experienced a $38 \%$ reduction in stroke incidence compared to those with SBP $\geq 150 \mathrm{mmHg}$, while those with SBP $<140 \mathrm{mmHg}$ had a $22 \%$ risk reduction that was not statistically significant. ${ }^{48}$ These findings not only suggest that BP reduction in the elderly is effective but also that there may be a moderate BP threshold below which there is no additional benefit.

The Swedish Trial in Old Patients with Hypertension (STOP-Hypertension-1) trial was a double-blind RCT in a Swedish cohort of hypertensive patients aged $70-84$ years. ${ }^{49}$ Entry criteria included $\mathrm{SBP} \geq 180 \mathrm{mmHg}$ and DBP $\geq 90 \mathrm{mmHg}$ or DBP $\geq 105 \mathrm{mmHg}$ regardless of SBP. Those randomized to the active treatment group received one of four regimens: atenolol, pindolol, metoprolol, or hydrochlorothiazide plus amiloride, as these were the most widely used medications in Sweden at the time. Beta-blocker could be added to diuretic and vice versa if needed for further BP control. After an average follow-up of 25 months, active treatment reduced the rate of composite endpoint (stroke and CV events) by $40 \%$ and mortality by $43 \%$, both statistically significant. The results of this study were published at a time when newer antihypertensive medications were becoming available, which led the STOP investigators to conduct a subsequent RCT that studied these newer agents in a larger cohort of elderly hypertensive patients in Sweden. In the STOP-Hypertension-2 trial, ${ }^{50} 6,614$ patients were randomized to one of three arms: conventional treatment, $\mathrm{CCB}$, or $\mathrm{ACE}$ inhibitor. Conventional treatment consisted of beta-blockers and/or diuretics. After 2 months, if BP was not controlled to a target $<160 / 95 \mathrm{mmHg}$, medications from other treatment arms could be added. Baseline BP was 194/98 mmHg in all three groups. After a mean follow-up of 60.3 months, $\mathrm{BP}$ reduction was similar among the groups, and almost half of patients were taking more than one antihypertensive medication at the last study visit. There was no significant difference in risk of the primary composite endpoint of fatal stroke, fatal MI, and other fatal CVD among the three groups. This study highlights an important feature of trials that compare medications between treatment groups in that patients may receive additional medications used in other treatment arms, which has the potential to bias results toward the null. Similarly, the benefits ascribed to a particular drug class may derive instead from a combination of drugs. 


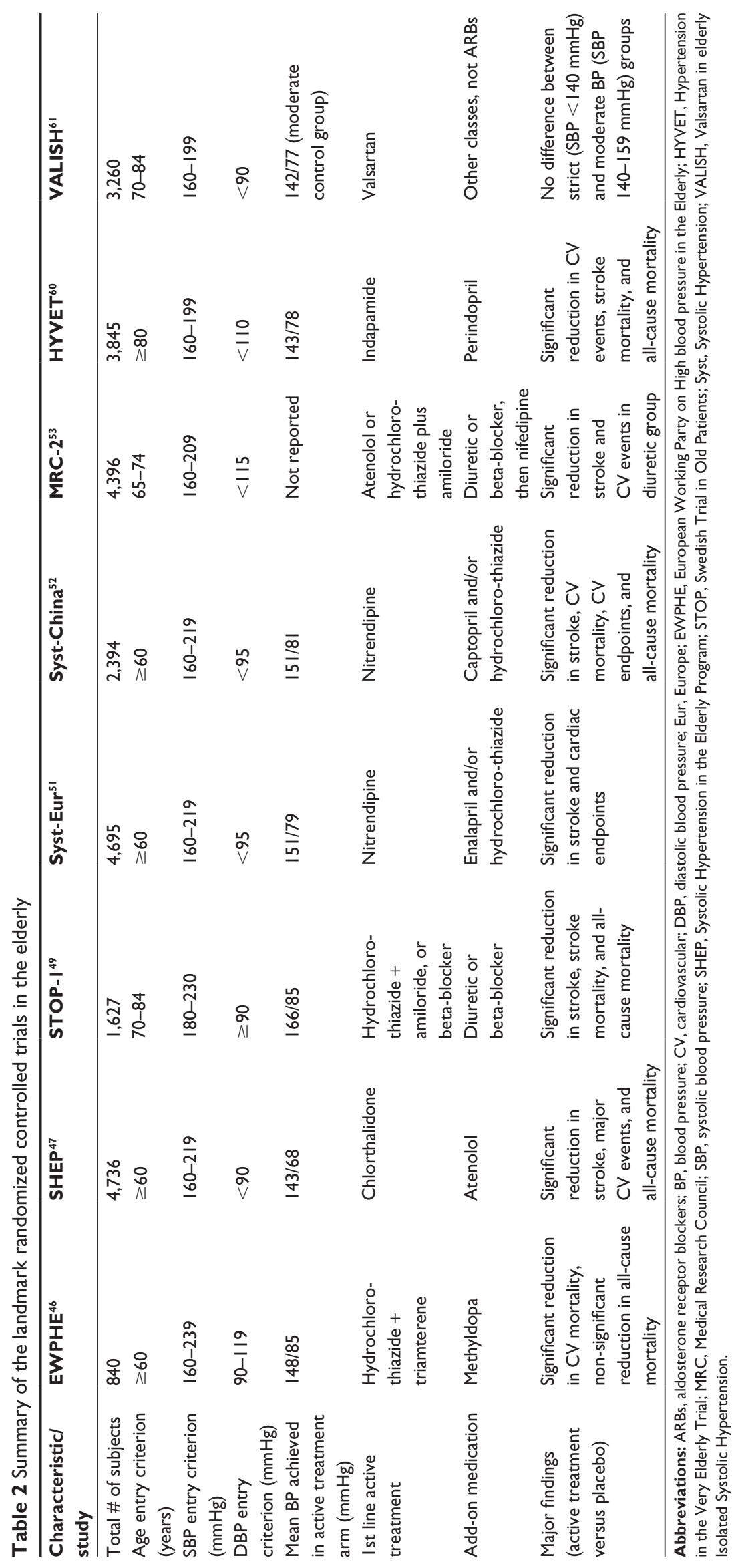


The Systolic Hypertension in Europe (Syst-Eur) and Systolic Hypertension in China (Syst-China) trials were two additional double-blind RCTs performed in Europe and the People's Republic of China, respectively. ${ }^{51,52}$ In both trials, active treatment group consisted of the dihydropyridine CCB nitrendipine with possible addition of $\mathrm{ACE}$ inhibitor and/or thiazide diuretic to achieve SBP $<150 \mathrm{mmHg}$ and reduction of $\geq 20 \mathrm{mmHg}$ from baseline. In the Syst-Eur trial, active treatment reduced mean BP from 174/86 mmHg to $151 / 79 \mathrm{mmHg}$ and significantly reduced the rate of stroke and cardiac endpoints. There was no reduction in all-cause mortality. In the Syst-China trial, active treatment had a slightly less potent effect on BP reduction compared to that in the latter trial and active treatment was associated with a $38 \%$ reduction in stroke, $37 \%$ reduction in CV endpoints, and 39\% reduction in all-cause mortality, all of which were statistically significant.

\section{Evidence for use of particular drug classes}

The Medical Research Council (MRC)-2 trial was a singleblind RCT that enrolled patients in the United Kingdom aged 65-74 years. ${ }^{53}$ Eligible subjects with SBP $160-209 \mathrm{mmHg}$ and DBP $<115 \mathrm{mmHg}$ were assigned to one of three groups: beta-blocker (atenolol), diuretic (hydrochlorothiazide plus amiloride), or placebo and were randomized in a 1:1:2 ratio, respectively. Each subject's target BP for the trial was determined by $\mathrm{BP}$ during a run-in period. For those whose SBP was $<180 \mathrm{mmHg}$ during the run-in period, target SBP was $\leq 150 \mathrm{mmHg}$; and for SBP of $\geq 180 \mathrm{mmHg}$ during the run-in period, target SBP was $\leq 160 \mathrm{mmHg}$. If target $\mathrm{BP}$ was not achieved during the trial, the subject received the other active drug in addition to the drug allocated by randomization. Additional antihypertensive medications were used if further BP control was needed despite this two-drug regimen. Participants were followed for a mean of 5.8 years. At 2 years, BP reduction was similar in the beta-blocker and diuretic arms. Compared with the diuretic arm, more patients in the beta-blocker arm required additional medication to achieve target BP (52\% versus $38 \%$ at 5 years), and more patients in the beta-blocker arm discontinued the drug due to either side effects or inadequate control. When the two active treatment groups were combined and compared with placebo, active treatment was associated with statistically significant $25 \%$ reduction in the rate of fatal or nonfatal stroke. Also, the number of $\mathrm{CV}$ events was significantly reduced in the combined treatment arms $(P=0.03)$. There was a trend toward fewer deaths in the treatment arms, which did not reach sta- tistical significance. Interestingly, the investigators detected a significant test of interaction between smoking status and treatment group for stroke events and CV events, such that the beneficial effect on stroke and $\mathrm{CV}$ event reduction in the treatment groups was confined to nonsmokers, though these findings should be interpreted with caution as they stem from a post hoc analysis. When diuretic was compared to placebo in multivariable models, diuretic was associated with a statistically significant reduced risk of stroke $(P=0.04), \mathrm{CV}$ event $(P=0.0005), \mathrm{CV}$ death $(P=0.03)$, and a trend toward decreased all-cause mortality (not significant). Atenolol did not reduce the risk of these outcomes. Furthermore, the benefit of diuretic compared to beta-blocker persisted after adjustment for change in BP from baseline, suggesting that the protective effects conferred by diuretic therapy are independent of changes in BP. The findings of this study are consistent with those of previous studies described above, supporting the treatment of elevated BP in elderly patients to reduce the risk of stroke and other important endpoints; and the results of the MRC-2 trial favor the use of diuretics as opposed to beta-blockers.

Subsequent studies have also demonstrated that betablocker based antihypertensive regimens are inferior to other regimens and therefore should not be used as first-line agents, especially in the elderly. ${ }^{54,55}$ One such study, the Losartan Intervention For Endpoint reduction in hypertension (LIFE) study, ${ }^{55}$ was a double-blind randomized trial that compared a losartan-based regimen to an atenolol-based regimen in patients aged 55-80 years with hypertension and LVH. After a mean follow-up of 4.7 years and similar BP reductions in the two groups, the group randomized to losartan had a $40 \%$ reduction in risk of stroke $(P=0.02)$.

The potential advantage of diuretics was demonstrated in the Antihypertensive and Lipid-Lowering Treatment to Prevent Heart Attack Trial (ALLHAT) ${ }^{56}$ This large, double-blind RCT compared the three treatment arms of chlorthalidone, lisinopril, and amlodipine in subjects aged 55 years or older (more than half were 65 years or older) with hypertension plus at least one additional CVD risk factor. When compared with chlorthalidone, the amlodipine group had a higher rate of heart failure, and the lisinopril group had higher rates of CVD, stroke, and heart failure - all statistically significant secondary endpoints. However, the purported superiority of a diuretic-based regimen has been questioned. In ALLHAT, there was no difference among the groups in the study's primary endpoint or all-cause mortality. Furthermore, SBP in the chlorthalidone group was controlled to a slightly but significantly lower level than the other 
groups, which likely explains at least some of the benefit appreciated in the chlorthalidone group.

However, in a subsequent RCT that compared ACE inhibitor to diuretic therapy in elderly Australian patients with hypertension, similar BP reduction was achieved at 5 years (26/12 mmHg in both groups); and there was a trend toward reduced risk of the primary outcome of cardiovascular events or all-cause mortality in the ACE inhibitor group, which was close to reaching statistical significance (hazard ratio 0.89 , $95 \%$ confidence interval $[\mathrm{CI}] 0.79-1.00, P=0.05) .{ }^{57}$ Diuretic therapy in combination with ACE inhibitor was found to be inferior to a combination of dihydropyridine CCB and ACE inhibitor in the Avoiding Cardiovascular Events through Combination Therapy in Patients Living with Systolic Hypertension (ACCOMPLISH) trial. ${ }^{58}$ This double-blind RCT randomized 11,506 hypertensive patients at high risk for $\mathrm{CV}$ events, approximately two-thirds of whom were $\geq 65$ years of age. Baseline BP was similar between groups and after a mean follow-up of 3 years, BP was lowered to 132/73 $\mathrm{mmHg}$ in the amlodipine/benazepril arm versus $133 / 74 \mathrm{mmHg}$ in the hydrochlorothiazide/benazepril arm, a small difference in BP between groups that was statistically significant $(P<0.001)$. Risk of the primary outcome of death from $\mathrm{CV}$ causes and $\mathrm{CV}$ events was reduced in the amlodipine/benazepril arm (hazard ratio $0.8, P<0.001$ ).

\section{BP treatment in the very elderly}

In the studies described above, a relatively small proportion of the study cohorts were comprised of patients older than 80 years. In 1999, Gueyffier et al for the Individual Data Analysis of Antihypertensive intervention (INDANA) group collected data from the subgroup of patients $\geq 80$ years of age included in RCTs and published their results in a meta-analysis. ${ }^{59} \mathrm{~A}$ pooled total of 1,670 study participants from seven trials, ranging from 7 to 650 subjects from each trial, were included in the analysis. Of these study participants, $76 \%$ were women, and a small proportion were smokers, diabetic, or had a history of stroke or myocardial infarction (MI). Compared to placebo, drug treatment was associated with a $34 \%$ reduction in risk of fatal or nonfatal stroke (95\% CI 48\%-92\%, $P=0.014)$. Treatment was also associated with reduced risk of major $\mathrm{CV}$ events and heart failure. There was no association between treatment group and mortality but a non-significant $6 \%$ increased mortality in the drug treatment group.

Following publication of this meta-analysis of subgroups, almost a decade passed before results of a trial that specifically enrolled very elderly patients was published. The Hyper- tension in the Very Elderly Trial (HYVET) was a double-blind RCT that randomized 3,845 patients who were 80 years of age or older with persistent SBP 160-199 $\mathrm{mmHg}$ to either the diuretic indapamide or placebo. ${ }^{60}$ Initially, the study protocol also required elevated DBP as an entry criterion, but the protocol was later amended in order to allow for recruitment of patients with ISH. The study was conducted in 195 centers across 13 countries. Target BP was 150/80 mmHg; and ACE inhibitor was added in the treatment group if necessary to achieve this goal BP. Subjects had a mean age 83.6 years and were followed for a median of 1.8 years. At 2 years, BP had fallen by $15 / 7 \mathrm{mmHg}$ and $30 / 13 \mathrm{mmHg}$ in the placebo and active treatment groups, respectively. The target BP was achieved in only $48.0 \%$ of the active treatment group but also in $19.9 \%$ of the placebo group $(P<0.001)$. Active treatment was associated with $30 \%$ reduction in the primary endpoint, fatal or nonfatal stroke, which was close to reaching statistical significance $(P=0.06)$. However, secondary endpoints that did reach statistical significance were a $21 \%$ reduction in rate of death from any cause $(P=0.02), 64 \%$ reduction in rate of heart failure $(P<0.001)$, and a $34 \%$ reduction in rate of any $\mathrm{CV}$ event $(P<0.001)$ in the active treatment group compared to placebo. The study found that the number of patients needed to be treated for 2 years to prevent one stroke was 94, which may even be an overestimate given that the patients enrolled in the study tended to be healthier than patients of similar age in the general population. Furthermore, roughly half of patients in the active treatment group achieved the target BP, thus underestimating the full effect of treatment.

The HYVET study highlighted the benefits of lowering BP in the very elderly, even to a modest target of $150 / 80 \mathrm{mmHg}$. The Valsartan in elderly Isolated Systolic Hypertension (VALISH) study was an RCT designed to compare the effect of strict SBP control $(<140 \mathrm{mmHg}$ ) versus moderate control ( $\geq 140 \mathrm{mmHg}$ and $<150 \mathrm{mmHg}$ ) on $\mathrm{CV}$ morbidity and mortality in elderly Japanese patients with ISH. ${ }^{61}$ This study included 3,260 participants aged 70 to 84 years. Valsartan was administered to all patients as the first antihypertensive medication with a dose increase in the first 2 months or addition of an alternate agent (except other ARBs) if needed to achieve the target BP as assigned by randomization. After 3 years of follow-up, mean BPs in the strict control and moderate control groups were $137 / 75 \mathrm{mmHg}$ and $142 / 77 \mathrm{mmHg}$, respectively $(P<0.001)$. The mean number of antihypertensive medications used was the same across groups, but those in the strict control group were on a higher dose of valsartan. The primary endpoint of the study was a composite of sudden death, fatal 
or nonfatal stroke, fatal or nonfatal MI, death due to heart failure, other CV death, unplanned hospitalization for CVD, and renal dysfunction. The strict control group had a slightly reduced rate of the composite endpoint compared to the moderate control group: 10.6 events per 1,000 patient-years versus 12.0 events per 1,000 patient-years, which was not statistically significant (hazard ratio $0.89,95 \%$ CI $0.60-1.31, P=0.38$ ). Furthermore, there were no differences between groups for each individual component of the composite endpoint. The VALISH study, however, was vastly underpowered due to an underestimation of event rate in this relatively healthy study population but confirmed the findings from a similar study in elderly Japanese patients that demonstrated no difference in primary endpoint between strict BP control ( $\mathrm{SBP}<140 \mathrm{mmHg}$ ) and moderate control (SBP $\geq 140 \mathrm{mmHg}$ and $<160 \mathrm{mmHg}$ ) groups. ${ }^{62}$ Given the available evidence, SBP reduction to a goal $<150 \mathrm{mmHg}$ may be sufficient to reduce $\mathrm{CV}$ risk.

Of note, the benefits of BP-lowering tend to be underestimated by the results of the aforementioned studies due to some patients in the placebo group (eg, approximately onethird in the SHEP trial) taking antihypertensive medication during the trial as stipulated in the study protocol for severely elevated BP coupled with an intention-to-treat analysis.

\section{Recommendations}

The treatment of hypertension in elderly patients is challenging due to risk of orthostatic hypotension, drug-drug interactions, adverse drug reactions, coexisting medical conditions, or barriers to adherence (including memory loss or drug cost). In addition, the risk of brain hypoperfusion via over-aggressive $\mathrm{BP}$ reduction is exacerbated by impaired cerebrovascular autoregulatory ability in elderly hypertensive patients. ${ }^{63}$

Lifestyle modifications should be recommended to all patients with hypertension. Prior to initiating drug therapy, it may be necessary to confirm a diagnosis of hypertension with ambulatory BP monitoring due to an increased prevalence of white-coat effect in the elderly. ${ }^{64}$ This temporary increase in autonomic activity has a greater effect on raising SBP than DBP and thus can mimic ISH. Furthermore, home BP has the added value of being a better predictor of $\mathrm{CV}$ morbidity and mortality than office BP. ${ }^{65}$ In addition, BP should be checked in supine, seated, and standing positions to assess for orthostatic changes.

$\mathrm{BP}$ reduction is probably more important than the use of a particular agent to accomplish BP reduction. ${ }^{66}$ Therefore, we recommend considering the individual patient's clinical history and comorbid conditions upon selection of an antihypertensive medication (Table 3). Given conflicting data regarding the superiority of a particular drug class, we recommend that use of thiazide diuretics, dihydropyridine CCBs, or ACE inhibitors/ARBs are all reasonable options as first-line therapy. Patients should be started on the lowest dose as the elderly are highly susceptible to volume contraction and electrolyte disturbances. Electrolytes should be monitored soon after drug initiation or dose changes. Combination therapy using diuretic plus ACE inhibitor, ARB, or potassiumsparing diuretic can be utilized to mitigate hypokalemia. Unless indicated for another medical condition (eg, prior MI, heart failure, or arrhythmia), use of beta blockers should be minimized or avoided. Finally, use of the centrally-acting alpha-2 adrenergic agonist clonidine should be avoided due to an unfavorable side effect profile.

As SBP increases almost linearly with age and the DBP declines as a manifestation of age-related increased arterial stiffness, most elderly patients have predominantly systolic hypertension; and in elderly patients, elevated SBP is a stronger predictor of cardiovascular risk than DBP. Therefore, treatment goals should probably be focused on SBP readings, as suggested in the JNC VII guidelines. The American College of Cardiology Foundation/American Heart Association (ACCF/AHA) 2011 guidelines on hypertension management in the elderly recommend an SBP goal $<140 \mathrm{mmHg}$ for most patients less than 80 years of age, and for patients $\geq 80$ years old, a goal of $140-145 \mathrm{mmHg}$ is acceptable. ${ }^{67}$ The JNC VII guidelines, which are from 2003 and are in the process of being updated, had recommended an SBP goal of $<140 \mathrm{mmHg}$ for all patients without comorbidities and lacked any specific SBP goals for the elderly. The $2013 \mathrm{ESH} / \mathrm{ESC}$ guidelines recommend an SBP goal of $140-150 \mathrm{mmHg}$ in patients greater than 80 years old. In fit patients less than 80 years old, an SBP less than $140 \mathrm{mmHg}$ can be considered; and in the fragile elderly population, SBP goals should be adapted to individual tolerability. ${ }^{43}$

Table 4 contrasts our recommendations with those of other recent guidelines; and the level of evidence supporting these recommendations varies. Given the available evidence summarized in detail above, we recommend an SBP target of $<140 \mathrm{mmHg}$ for patients less than 80 years of age (which is largely opinion-based but consistent with recommendations by major guideline committees) and an SBP target of 140-150 $\mathrm{mmHg}$ in patients older than 80 years of age. The latter level of BP both approximates the mean BP achieved in the active treatment arm of RCTs and avoids the risk of hypoperfusion. Furthermore, the results of studies in 
Table 3 Features of various classes of antihypertensive medications

\begin{tabular}{|c|c|c|c|c|}
\hline Class & $\begin{array}{l}\text { Common generic } \\
\text { drug names }\end{array}$ & $\begin{array}{l}\text { Compelling } \\
\text { indications }\end{array}$ & Side effects & Warnings/notes \\
\hline $\begin{array}{l}\text { Thiazide or thiazide-like } \\
\text { diuretic }\end{array}$ & $\begin{array}{l}\text { Chlorthalidone } \\
\text { Hydrochlorothiazide } \\
\text { Indapamide } \\
\text { Metolazone }\end{array}$ & Low EF & $\begin{array}{l}\text { Hypokalemia, hyponatremia, } \\
\text { hyperuricemia, hypocalciuria, } \\
\text { hyperglycemia, rash }\end{array}$ & $\begin{array}{l}\text { May improve calcium balance } \\
\text { in osteopenia/osteoporosis. } \\
\text { Avoid if allergic to sulfa. } \\
\text { May precipitate volume } \\
\text { contraction. }\end{array}$ \\
\hline Loop diuretic & $\begin{array}{l}\text { Bumetanide } \\
\text { Ethacrynic acid } \\
\text { Furosemide } \\
\text { Torsemide }\end{array}$ & Low EF & $\begin{array}{l}\text { Hypokalemia, hyperuricemia, } \\
\text { rash }\end{array}$ & $\begin{array}{l}\text { Avoid if allergic to sulfa } \\
\text { (except ethacrynic acid). } \\
\text { May precipitate volume } \\
\text { contraction. }\end{array}$ \\
\hline $\begin{array}{l}\text { Potassium-sparing } \\
\text { diuretic }\end{array}$ & $\begin{array}{l}\text { Amiloride } \\
\text { Triamterene }\end{array}$ & $\begin{array}{l}\text { Rare etiologies of } \\
\text { secondary hypertension } \\
\text { (eg, Liddle's syndrome) }\end{array}$ & Hyperkalemia & $\begin{array}{l}\text { Useful in combination with } \\
\text { other diuretic classes. Weak } \\
\text { agents when used alone. }\end{array}$ \\
\hline ACE inhibitor & $\begin{array}{l}\text { Benazepril } \\
\text { Captopril } \\
\text { Enalapril } \\
\text { Lisinopril } \\
\text { Quinapril } \\
\text { Ramipril }\end{array}$ & $\begin{array}{l}\text { Post-MI, low EF, } \\
\text { proteinuric CKD }\end{array}$ & $\begin{array}{l}\text { Cough, hyperkalemia, } \\
\text { increased } \mathrm{SCr}\end{array}$ & $\begin{array}{l}\text { Risk of angioedema. } \\
\text { Contraindicated in pregnancy. }\end{array}$ \\
\hline ARB & $\begin{array}{l}\text { Candesartan } \\
\text { Irbesartan } \\
\text { Losartan } \\
\text { Olmesartan } \\
\text { Telmisartan } \\
\text { Valsartan }\end{array}$ & $\begin{array}{l}\text { Post-MI, low EF, } \\
\text { proteinuric CKD }\end{array}$ & Hyperkalemia, increased SCr & $\begin{array}{l}\text { Alternative to ACE inhibitor. } \\
\text { Less risk of angioedema. } \\
\text { Contraindicated in pregnancy. }\end{array}$ \\
\hline MRA & $\begin{array}{l}\text { Eplerenone } \\
\text { Spironolactone }\end{array}$ & $\begin{array}{l}\text { Primary aldosteronism, } \\
\text { low EF, proteinuric CKD }\end{array}$ & $\begin{array}{l}\text { Hyperkalemia, increased } \\
\text { SCr, irregular menses, } \\
\text { gynecomastia }\end{array}$ & $\begin{array}{l}\text { Estrogenic effects rare with } \\
\text { eplerenone. }\end{array}$ \\
\hline $\begin{array}{l}\text { Calcium channel } \\
\text { blocker }\end{array}$ & $\begin{array}{l}\text { Amlodipine } \\
\text { Diltiazem (non) } \\
\text { Nifedipine } \\
\text { Verapamil (non) }\end{array}$ & $\begin{array}{l}\text { Atrial arrhythmia (non), } \\
\text { Raynaud's syndrome }\end{array}$ & Edema, fatigue & $\begin{array}{l}\text { Avoid in } 2 \text { nd or } 3 r d \text { degree } \\
\text { heart block or heart failure } \\
\text { (non). }\end{array}$ \\
\hline Beta-blocker & $\begin{array}{l}\text { Atenolol } \\
\text { Carvedilol }(\alpha) \\
\text { Labetalol }(\alpha) \\
\text { Metoprolol } \\
\text { Nebivolol }\end{array}$ & $\begin{array}{l}\text { Angina, atrial arrhythmia, } \\
\text { post-MI, low EF, } \\
\text { hyperthyroidism }\end{array}$ & $\begin{array}{l}\text { Bronchospasm, fatigue, } \\
\text { depression, impotence }\end{array}$ & $\begin{array}{l}\text { Avoid in } 2 \text { nd or } 3 \text { rd degree } \\
\text { heart block. }\end{array}$ \\
\hline Direct vasodilator & $\begin{array}{l}\text { Hydralazine } \\
\text { Minoxidil }\end{array}$ & $\begin{array}{l}\text { Low EF (hydralazine plus } \\
\text { nitrate as alternative to } \\
\text { ACE inhibitor/ARB) }\end{array}$ & $\begin{array}{l}\text { Edema, flushing, hair } \\
\text { growth (minoxidil) }\end{array}$ & $\begin{array}{l}\text { Minoxidil may cause } \\
\text { pericardial effusion with } \\
\text { tamponade. }\end{array}$ \\
\hline
\end{tabular}

Abbreviations: ARB, angiotensin receptor blocker; $\alpha$, alpha- and beta-blocking activity; EF, ejection fraction; SCr, serum creatinine; MRA, mineralocorticoid receptor antagonist; non, non-dihydropyridine; MI, myocardial infarction; CKD, chronic kidney disease; ACE, angiotensin converting enzyme.

Table 4 SBP targets in the elderly provided by various groups

\begin{tabular}{|c|c|c|c|}
\hline $\begin{array}{l}\text { Guideline } \\
\text { committee/group }\end{array}$ & $\begin{array}{l}\text { Year } \\
\text { published }\end{array}$ & $\begin{array}{l}\text { SBP target } \\
<80 \text { years of } \\
\text { age }(\mathrm{mmHg})\end{array}$ & $\begin{array}{l}\text { SBP target } \\
\geq 80 \text { years of } \\
\text { age }(\mathrm{mmHg})\end{array}$ \\
\hline $\mathrm{JNC} \mathrm{VII}{ }^{42}$ & 2003 & $<140$ & $<140$ \\
\hline ACCF/AHA ${ }^{67}$ & 2011 & $<140$ & $|40-| 45$ \\
\hline $\mathrm{ESH} / \mathrm{ESC}^{43}$ & 2013 & $\begin{array}{l}<140 \text { in fit } \\
\text { individuals }\end{array}$ & $140-150$ \\
\hline Denker and Cohen & 2013 & $<140$ & $140-150$ \\
\hline
\end{tabular}

Abbreviations: ACCF/AHA, American College of Cardiology Foundation/American Heart Association; ESH/ESC, European Society of Hypertension/European Society of Cardiology; JNC, Joint National Committee on Prevention, Detection, Evaluation, and Treatment of High Blood Pressure; SBP, systolic blood pressure. very elderly Japanese patients did not demonstrate a benefit from more aggressive BP control. In addition to providing CV benefit, SBP in the $135-150 \mathrm{mmHg}$ range seems to be protective in reducing the rate of cognitive decline compared with $\mathrm{SBP}<135$ or $>150 \mathrm{mmHg} .{ }^{68}$ At this time, there is insufficient evidence to suggest different BP targets for elderly patients with diabetes mellitus or chronic kidney disease. Our simplified yet evidence-based recommendations may serve to minimize physician related barriers to treatment success and reduce the morbidity associated with hypertension in the elderly. 


\section{Acknowledgments}

Grant support was obtained from the National Institute Of Diabetes And Digestive And Kidney Diseases of the National Institutes of Health (NIDDK/NIH) award F32DK098914 [MD].

\section{Disclosure}

The authors report no conflicts of interest in this work.

\section{References}

1. He W, Sengupta M, Velkoff VA, DeBarros KA; for the US Census Bureau. Current Population Reports, 65 in the United States: 2005. Washington, DC: US Government Printing Office; 2005: P23-P209.

2. Ostchega Y, Dillon CF, Hughes JP, Carroll M, Yoon S. Trends in hypertension prevalence, awareness, treatment, and control in older US adults: data from the National Health and Nutrition Examination Survey 1988 to 2004. J Am Geriatr Soc. 2007;55(7):1056-1065.

3. Vasan RS, Beiser A, Seshadri S, et al. Residual lifetime risk for developing hypertension in middle-aged women and men: The Framingham Heart Study. JAMA. 2002;287(8):1003-1010.

4. Calhoun DA, Jones D, Textor S, et al. Resistant hypertension: diagnosis, evaluation, and treatment. A scientific statement from the American Heart Association Professional Education Committee of the Council for High Blood Pressure Research. Hypertension. 2008; 51(6):1403-1419.

5. Hayes DK, Denny CH, Keenan NL, Croft JB, Greenlund KJ. Healthrelated quality of life and hypertension status, awareness, treatment, and control: National Health and Nutrition Examination Survey, 2001-2004. J Hypertens. 2008;26(4):641-647.

6. Lawes CM, Vander Hoorn S, Rodgers A; International Society of Hypertension. Global burden of blood-pressure-related disease, 2001. Lancet. 2008;371(9623):1513-1518.

7. Lewington S, Clarke R, Qizilbash N, Peto R, Collins R; Prospective Studies Collaboration. Age-specific relevance of usual blood pressure to vascular mortality: a meta-analysis of individual data for one million adults in 61 prospective studies. Lancet. 2002;360(9349): 1903-1913.

8. Gorelick PB, Sacco RL, Smith DB, et al. Prevention of a first stroke: a review of guidelines and a multidisciplinary consensus statement from the National Stroke Association. JAMA. 1999;281(12):1112-1120.

9. Franklin SS, Jacobs MJ, Wong ND, L'Italien GJ, Lapuerta P. Predominance of isolated systolic hypertension among middle-aged and elderly US hypertensives: analysis based on National Health and Nutrition Examination Survey (NHANES) III. Hypertension. 2001;37(3):869-874.

10. Franklin SS, Larson MG, Khan SA, et al. Does the relation of blood pressure to coronary heart disease risk change with aging? The Framingham Heart Study. Circulation. 2001;103(9):1245-1249.

11. Burt VL, Whelton P, Roccella EJ, et al. Prevalence of hypertension in the US adult population. Results from the Third National Health and Nutrition Examination Survey, 1988-1991. Hypertension. 1995;25(3):305-313.

12. Ungvari Z, Kaley G, de Cabo R, Sonntag WE, Csiszar A. Mechanisms of vascular aging: new perspectives. J Gerontol A Biol Sci Med Sci. 2010;65(10):1028-1041.

13. Wang M, Takagi G, Asai K, et al. Aging increases aortic MMP-2 activity and angiotensin II in nonhuman primates. Hypertension. 2003;41(6): 1308-1316.

14. Wang M, Zhang J, Spinetti G, et al. Angiotensin II activates matrix metalloproteinase type II and mimics age-associated carotid arterial remodeling in young rats. Am J Pathol. 2005;167(5):1429-1442.
15. Chabrashvili T, Kitiyakara C, Blau J, et al. Effects of ANG II type 1 and 2 receptors on oxidative stress, renal NADPH oxidase, and SOD expression. Am J Physiol Regul Integr Comp Physiol. 2003;285(1): R117-R124.

16. Basso N, Cini R, Pietrelli A, Ferder L, Terragno NA, Inserra F. Protective effect of long-term angiotensin II inhibition. Am J Physiol Heart Circ Physiol. 2007;293(3):H1351-H1358.

17. Lakatta EG. Cardiovascular regulatory mechanisms in advanced age. Physiol Rev. 1993;73(2):413-467.

18. Gribbin B, Pickering TG, Sleight P, Peto R. Effect of age and high blood pressure on baroreflex sensitivity in man. Circ Res. 1971;29(4):424 431.

19. Vita JA, Keaney JF. Exercise - toning up the endothelium? $N$ Engl J Med. 2000;342(7):503-505.

20. Ulker S, McKeown PP, Bayraktutan U. Vitamins reverse endothelial dysfunction through regulation of eNOS and NAD(P)H oxidase activities. Hypertension. 2003;41(3):534-539.

21. d'Uscio LV, Milstien S, Richardson D, Smith L, Katusic ZS. Long-term vitamin $\mathrm{C}$ treatment increases vascular tetrahydrobiopterin levels and nitric oxide synthase activity. Circ Res. 2003;92(1):88-95.

22. Yusuf S, Dagenais G, Pogue J, Bosch J, Sleight P. Vitamin E supplementation and cardiovascular events in high-risk patients. The Heart Outcomes Prevention Evaluation Study Investigators. $N$ Engl J Med. 2000;342(3):154-160.

23. Heart Protection Study Collaborative Group. MRC/BHF Heart Protection Study of antioxidant vitamin supplementation in 20,536 high-risk individuals: a randomised placebo-controlled trial. Lancet. 2002; 360(9326):23-33.

24. de Gaetano G; Collaborative Group of the Primary Prevention Project. Low-dose aspirin and vitamin E in people at cardiovascular risk: a randomised trial in general practice. Collaborative Group of the Primary Prevention Project. Lancet. 2001;357(9250):89-95.

25. Ghiadoni L, Magagna A, Versari D, et al. Different effect of antihypertensive drugs on conduit artery endothelial function. Hypertension. 2003;41(6):1281-1286.

26. Berry C, Anderson N, Kirk AJ, Dominiczak AF, McMurray JJ. Renin angiotensin system inhibition is associated with reduced free radical concentrations in arteries of patients with coronary heart disease. Heart. 2001;86(2):217-220.

27. On YK, Kim CH, Oh BH, Lee MM, Park YB. Effects of angiotensin converting enzyme inhibitor and calcium antagonist on endothelial function in patients with essential hypertension. Hypertens Res. 2002;25(3):365-371.

28. Mason RP, Marche P, Hintze TH. Novel vascular biology of thirdgeneration L-type calcium channel antagonists: ancillary actions of amlodipine. Arterioscler Thromb Vasc Biol. 2003;23(12):2155-2163.

29. Collins R, MacMahon S. Blood pressure, antihypertensive drug treatment and the risks of stroke and of coronary heart disease. Br Med Bull. 1994;50(2):272-298.

30. Staessen JA, Gasowski J, Wang JG, et al. Risks of untreated and treated isolated systolic hypertension in the elderly: meta-analysis of outcome trials. Lancet. 2000;355(9207):865-872.

31. Julius S, Kjeldsen SE, Weber M, et al; VALUE trial group. Outcomes in hypertensive patients at high cardiovascular risk treated with regimens based on valsartan or amlodipine: the VALUE randomised trial. Lancet. 2004;363(9426):2022-2031.

32. Messerli FH, Mancia G, Conti CR, et al. Dogma disputed: can aggressively lowering blood pressure in hypertensive patients with coronary artery disease be dangerous? Ann Intern Med. 2006;144(12):884-893.

33. Sleight P, Redon J, Verdecchia P, et al; ONTARGET investigators Prognostic value of blood pressure in patients with high vascular risk in the Ongoing Telmisartan Alone and in combination with Ramipril Global Endpoint Trial study. J Hypertens. 2009;27(7):1360-1369.

34. Bangalore S, Messerli FH, Wun CC, et al; Treating to New Targets Steering Committee and Investigators. J-curve revisited: An analysis of blood pressure and cardiovascular events in the Treating to New Targets (TNT) Trial. Eur Heart J. 2010;31(23):2897-2908. 
35. Boshuizen HC, Izaks GJ, van Buuren S, Ligthart GJ. Blood pressure and mortality in elderly people aged 85 and older: community based study. BMJ. 1998;316(7147):1780-1784.

36. Langer RD, Ganiats TG, Barrett-Connor E. Factors associated with paradoxical survival at higher blood pressures in the very old. Am J Epidemiol. 1991;134(1):29-38.

37. Hakala SM, Tilvis RS, Strandberg TE. Blood pressure and mortality in an older population. A 5-year follow-up of the Helsinki Ageing Study. Eur Heart J. 1997;18(6):1019-1023.

38. van Bemmel T, Gussekloo J, Westendorp RG, Blauw GJ. In a populationbased prospective study, no association between high blood pressure and mortality after age 85 years. J Hypertens. 2006;24(2):287-292.

39. Molander L, Lövheim H, Norman T, Nordström P, Gustafson Y. Lower systolic blood pressure is associated with greater mortality in people aged 85 and older. JAm Geriatr Soc. 2008;56(10):1853-1859.

40. Satish S, Freeman DH, Ray L, Goodwin JS. The relationship between blood pressure and mortality in the oldest old. J Am Geriatr Soc. 2001;49(4):367-374.

41. Boutitie F, Gueyffier F, Pocock S, Fagard R, Boissel JP; INDANA Project Steering Committee. INdividual Data ANalysis of Antihypertensive intervention. J-shaped relationship between blood pressure and mortality in hypertensive patients: new insights from a meta-analysis of individual-patient data. Ann Intern Med. 2002;136(6):438-448.

42. Chobanian AV, Bakris GL, Black HR, et al; National Heart, Lung, and Blood Institute Joint National Committee on Prevention, Detection, Evaluation, and Treatment of High Blood Pressure; National High Blood Pressure Education Program Coordinating Committee. The Seventh Report of the Joint National Committee on Prevention, Detection, Evaluation, and Treatment of High Blood Pressure: the JNC 7 report. JAMA. 2003;289(19):2560-2572.

43. Mancia G, Fagard R, Narkiewicz K, et al. 2013 ESH/ESC guidelines for the management of arterial hypertension: the Task Force for the Management of Arterial Hypertension of the European Society of Hypertension (ESH) and of the European Society of Cardiology (ESC). Eur Heart J. 2013;34(28):2159-2219.

44. Brandão Rondon MU, Alves MJ, Braga AM, et al. Postexercise blood pressure reduction in elderly hypertensive patients. J Am Coll Cardiol. 2002;39(4):676-682.

45. Appel LJ, Espeland MA, Easter L, Wilson AC, Folmar S, Lacy CR. Effects of reduced sodium intake on hypertension control in older individuals: results from the Trial of Nonpharmacologic Interventions in the Elderly (TONE). Arch Intern Med. 2001;161(5):685-693.

46. Amery A, Birkenhager W, Brixko P, et al. Mortality and morbidity results from the European Working Party on High Blood Pressure in the Elderly trial. Lancet. 1985;1(8442):1349-1354.

47. Prevention of stroke by antihypertensive drug treatment in older persons with isolated systolic hypertension. Final results of the Systolic Hypertension in the Elderly Program (SHEP). SHEP Cooperative Research Group. JAMA. 1991;265(24):3255-3264.

48. Perry HM, Davis BR, Price TR, et al. Effect of treating isolated systolic hypertension on the risk of developing various types and subtypes of stroke: the Systolic Hypertension in the Elderly Program (SHEP). JAMA. 2000;284(4):465-471.

49. Dahlöf B, Lindholm LH, Hansson L, Scherstén B, Ekbom T, Wester PO. Morbidity and mortality in the Swedish Trial in Old Patients with Hypertension (STOP-Hypertension). Lancet. 1991;338(8778):1281-1285.

50. Hansson L, Lindholm LH, Ekbom T, et al. Randomised trial of old and new antihypertensive drugs in elderly patients: cardiovascular mortality and morbidity the Swedish Trial in Old Patients with Hypertension-2 study. Lancet. 1999;354(9192):1751-1756.

51. Staessen JA, Fagard R, Thijs L, et al. Randomised double-blind comparison of placebo and active treatment for older patients with isolated systolic hypertension. The Systolic Hypertension in Europe (Syst-Eur) Trial Investigators. Lancet. 1997;350(9080):757-764.
52. Liu L, Wang JG, Gong L, Liu G, Staessen JA. Comparison of active treatment and placebo in older Chinese patients with isolated systolic hypertension. Systolic Hypertension in China (Syst-China) Collaborative Group. J Hypertens. 1998;16(12 Pt 1):1823-1829.

53. Medical Research Council trial of treatment of hypertension in older adults: principal results. MRC Working Party. BMJ. 1992;304(6824): 405-412.

54. Khan N, McAlister FA. Re-examining the efficacy of beta-blockers for the treatment of hypertension: a meta-analysis. CMAJ. 2006;174(12): $1737-1742$

55. Dahlöf B, Devereux RB, Kjeldsen SE, et al; LIFE Study Group. Cardiovascular morbidity and mortality in the Losartan Intervention For Endpoint reduction in hypertension study (LIFE): a randomised trial against atenolol. Lancet. 2002;359(9311):995-1003.

56. ALLHAT Officers and Coordinators for the ALLHAT Collaborative Research Group. The Antihypertensive and Lipid-Lowering Treatment to Prevent Heart Attack Trial. Major outcomes in high-risk hypertensive patients randomized to angiotensin-converting enzyme inhibitor or calcium channel blocker vs diuretic: The Antihypertensive and LipidLowering Treatment to Prevent Heart Attack Trial (ALLHAT). JAMA. 2002;288(23):2981-2997.

57. Wing LM, Reid CM, Ryan P, et al; Second Australian National Blood Pressure Study Group. A comparison of outcomes with angiotensinconverting - enzyme inhibitors and diuretics for hypertension in the elderly. $N$ Engl J Med. 2003;348(7):583-592.

58. Jamerson K, Weber MA, Bakris GL, et al; ACCOMPLISH Trial Investigators. Benazepril plus amlodipine or hydrochlorothiazide for hypertension in high-risk patients. $N$ Engl J Med. 2008;359(23): $2417-2428$.

59. Gueyffier F, Bulpitt C, Boissel JP, et al. Antihypertensive drugs in very old people: a subgroup meta-analysis of randomised controlled trials. INDANA Group. Lancet. 1999;353(9155):793-796.

60. Beckett NS, Peters R, Fletcher AE, et al; HYVET Study Group. Treatment of hypertension in patients 80 years of age or older. $N$ Engl J Med. 2008;358(18):1887-1898.

61. Ogihara T, Saruta T, Rakugi H, et al; Valsartan in Elderly Isolated Systolic Hypertension Study Group. Target blood pressure for treatment of isolated systolic hypertension in the elderly: valsartan in elderly isolated systolic hypertension study. Hypertension. 2010;56(2):196-202.

62. JATOS Study Group. Principal results of the Japanese trial to assess optimal systolic blood pressure in elderly hypertensive patients (JATOS). Hypertens Res. 2008;31(12):2115-2127.

63. Strandgaard S. Cerebral blood flow in the elderly: impact of hypertension and antihypertensive treatment. Cardiovasc Drugs Ther. 1991; 4 Suppl 6:1217-1221.

64. Mansoor GA, McCabe EJ, White WB. Determinants of the whitecoat effect in hypertensive subjects. J Hum Hypertens. 1996;10(2): 87-92.

65. Ward AM, Takahashi O, Stevens R, Heneghan C. Home measurement of blood pressure and cardiovascular disease: systematic review and meta-analysis of prospective studies. $J$ Hypertens. 2012;30(3): 449-456.

66. Wang JG, Staessen J. Benefits of antihypertensive pharmacologic therapy and blood pressure reduction in outcome trials. J Clin Hypertens (Greenwich). 2003;5(1):66-75.

67. Aronow WS, Fleg JL, Pepine CJ, et al; ACCF Task Force. ACCF/ AHA 2011 expert consensus document on hypertension in the elderly: a report of the American College of Cardiology Foundation Task Force on Clinical Expert Consensus Documents. Circulation. 2011; 123(21):2434-2506.

68. Sacktor N, Gray S, Kawas C, Herbst J, Costa P, Fleg J. Systolic blood pressure within an intermediate range may reduce memory loss in an elderly hypertensive cohort. J Geriatr Psychiatry Neurol. 1999; 12(1):1-6. 
Clinical Interventions in Aging

\section{Publish your work in this journal}

Clinical Interventions in Aging is an international, peer-reviewed journal focusing on evidence-based reports on the value or lack thereof of treatments intended to prevent or delay the onset of maladaptive correlates of aging in human beings. This journal is indexed on PubMed Central, MedLine, the American Chemical Society's 'Chemical Abstracts

Service' (CAS), Scopus and the Elsevier Bibliographic databases. The manuscript management system is completely online and includes a very quick and fair peer-review system, which is all easy to use. Visit $\mathrm{http}: / /$ www.dovepress.com/testimonials.php to read real quotes from published authors.

Submit your manuscript here: http://www.dovepress.com/clinical-interventions-in-aging-journal 